\title{
Physicochemical Changes and Antioxidant Activity of Juice, Skin, Pellicle and Seed of Pomegranate (cv. Mollar de Elche) at Different Stages of Ripening
}

\author{
Luana Fernandes ${ }^{1}$, José Alberto C. Pereira ${ }^{1}$, Isabel Lopéz-Cortés², Domingo M. Salazar ${ }^{2}$ \\ and Elsa C. D. Ramalhosa ${ }^{1 *}$ \\ ${ }^{1}$ Mountain Research Centre (CIMO), School of Agriculture, Polytechnic Institute of Bragança, \\ Campus de Sta Apolónia, Apartado 1172, PT-5301-855 Bragança, Portugal \\ ${ }^{2}$ Department of Agronomy, Polytechnic University of Valencia, Camino de Vera s/n, \\ ES-46022 Valencia, Spain \\ Received: January 9, 2015 \\ Accepted: May 22, 2015
}

\begin{abstract}
Summary
In the present work, we investigate how the degree of ripeness (low, low-medium, medium and medium-high) affects the physical and compositional changes, as well as antioxidant properties of pomegranate fruit (cv. Mollar de Elche). The skin, pellicle, seed and juice were analysed. The fruit mass increased and the fruit skin became reddish (higher $a^{*}$ and lower $h^{*}$ ) as the fruit ripening progressed. The lowest concentrations of flavonoids and hydrolysable tannins were recorded in skin and pellicles at medium-high maturity stage, which explains the decrease in the total phenols and reducing power during ripening of pomegranate. On the contrary, the highest concentration of flavonoids (165 mg of quercetin equivalents per $100 \mathrm{~mL}$ of juice) was determined in the juice at the most advanced ripening stage, concomitant with the highest total phenols $(1695 \mathrm{mg}$ of gallic acid equivalents per $100 \mathrm{~mL}$ of juice). Higher DPPH scavenging activity and an increase in the reducing power of juice were also observed during ripening. The trend of the above-mentioned properties allowed describing the fruit development and maturity.
\end{abstract}

Key words: Mollar de Elche cultivar, fruit constituents, ripening stages, physicochemical properties, antioxidant activity

\section{Introduction}

Spain is considered one of the most important producers of pomegranate in Europe. Its production is concentrated in the Communities of Valencia, Andalusia and Murcia (1); however, $90 \%$ of the production is from Alicante (in the south of Valencian Community), more specifically of the municipalities of Elche, Albatera and Crevillente, in order of importance (2).

The main cultivar planted in Spain is Mollar de Elche, followed by Valenciana (3). Nevertheless, some authors also refer to White as an important cultivar (4). Mollar de
Elche cultivar is referred to as one of the most prized in the world because of its remarkable flavour and high concentration of antioxidants (5). Moreover, different characteristics of cultivars may also be due to their different harvest periods. Valenciana cultivar, for example, is harvested in early August (3), with very little sun damage and lower risk of pest attack or bad weather, but it has low yield, average to poor internal fruit quality, and small fruit size (3). On the other hand, Mollar de Elche cultivar is harvested much later (late September to mid-November) (3), providing more sun damage and cuts. However, it is characterised by greater productivity, excellent quality, 
larger fruits and better acceptance by consumers (3). Thus, the harvesting time is an aspect of particular importance since an early harvest may inhibit the development of the characteristic colour, flavour and aroma of pomegranate, while fruits harvested too late may have a reduced shelf life and greater sensitivity to disease (6).

During the development and growth, the fruit passes through various stages of ripening, which result in a variety of physiological, biochemical and structural processes (7). The chemical changes that occur during fruit ripening will affect the nutritional and beneficial health properties of pomegranate, so it is important that they are harvested in a good ripening stage (6) because it will affect fruit quality and the damage that may arise during their storage (8). In addition to cultivar and ripening stage, the fruit quality is also strongly dependent on farming region, climate and cultural practices $(9,10)$.

Some studies have been carried out to follow pomegranate ripening, focusing on phenolic and mineral contents in skin $(5,6,9)$ and on the chemical properties and antioxidant activity of arils $(6,8,9,11,12)$. Concerning juices, physicochemical properties were determined during the 26th and 32nd week, in three stages of ripening, and between the 20th and 140th day after fruit setting by Gil et al. (11), Al-Maiman and Ahmad (12) and Zarei et al. (13), respectively. Previously, Hernández et al. (14) had studied the evolution of anthocyanins during ripening of new clones of pomegranate, namely ME16, VA1, PTO8, BA1 and MA2. Generally, the studies performed until now have shown that total phenolic content increased at an early stage of growth but thereafter decreased during maturation. However, some exceptions were observed.

A few studies have been conducted on both the chemical composition and antioxidant activity of different pomegranate constituents. Eghdami et al. (15), for example, studied the antioxidant activity in the skin and juice of three pomegranate cultivars, Elfalleh et al. (16) investigated phenolic compounds and antioxidant activity in the skin, seed, leaf and flower of three cultivars, and Gözlekçi et al. (17) determined the phenolic compound contents in seeds, juice and skin of four pomegranate cultivars. Nevertheless, so far, no study has been performed on physicochemical changes and antioxidant activity of several pomegranate components (e.g. skin, pellicle, arils and juice) during ripening. Skin and seeds are by-products of pomegranate juice industry, representing an additional cost for companies and they may also cause serious environmental problems. On the other hand, they are considered a cheap source of valuable components, allowing the recovery of target compounds to be used as functional additives in different products such as food and cosmetics.

The main objectives of the present study are to investigate the changes observed in the skin colour of the fruit, in the length and diameter of the seed, as well as the $\mathrm{pH}$ and total soluble solids and total monomeric anthocyanin contents in pomegranate juice during ripening. Simultaneously, the contents of hydrolysable tannins, flavonoids and total phenols, as well as the antioxidant activity (DPPH radical scavenging activity and reducing power), were determined in four pomegranate components, namely, skin, pellicle, juice and seed, during four ripening stages (low, low-medium, medium and medium-high) of Mollar de Elche cultivar. This cultivar has been chosen because it is one of the most consumed in Spain and highly appreciated by consumers. Furthermore, new knowledge into physicochemical and biological properties of each pomegranate components during ripening of Mollar de Elche cultivar will be achieved in order to valorise some of its components.

\section{Materials and Methods}

\section{Pomegranate samples}

The pomegranate cultivar studied in this work was Mollar de Elche from Valencia, Spain. The fruits were collected at four ripening stages (Fig. 1), namely low, low-medium, medium and medium-high, taking into account the colour of the fruit skin. The low ripening stage is characterised by immature pomegranates with green skin colour, the low-medium is an early ripening stage in which the skin colour is still green or yellow-green, medium stage pomegranates with reddish-yellow colour are suitable for the export market, and the medium-high stage includes ripe pomegranates with reddish skin colour (Fig. 1a). The selected ripening stages corresponded to the $\mathrm{BBCH} 81,83,85$ and 87 indices, according to Meier (18) and Melgarejo and Salazar (19).

Three lots of samples at each ripening stage were made, each containing three fruits, collected from different trees in the same experimental field. Each lot was analysed in duplicate. The fruits were transported to the laboratory under refrigeration conditions. Then, each pomegranate was separated into its components, namely, arils, skin and pellicle (Figs. 1b-d). After freezing, the skin and pellicle were lyophilized (Scanvac, Coolsafe, Lynge, Denmark) for 2 days. The arils were frozen until further use. The juice was extracted by squeezing the seeds without crushing them, and stored frozen; the seeds without juice were also stored for further analysis (Figs. 1e and f).

\section{Fruit colour and seed dimensions}

The skin colour was evaluated in three pomegranates at each ripening stage (five readings per fruit) with a colourimeter Minolta CR-400 (Osaka, Japan) using CIELab scale. $L^{*}, a^{*}$ and $b^{*}$ coordinates were measured, where $L^{*}$ varies between 0 (completely black) and 100 (completely white), $a^{*}$ between -100 (green) and +100 (red), and $b^{*}$ between -100 (blue) and +100 (yellow). Furthermore, the chroma $\left(C^{*}\right)$ and hue angle $\left(h^{*}\right)$ values were determined according to Zaouay et al. (20) and Manera et al. (5) by the following equations:

$$
\begin{aligned}
& C^{*}=\left(a^{* 2}+b^{* 2}\right)^{1 / 2} \\
& h^{*}=\tan ^{-1}\left(b^{*} / a^{*}\right)
\end{aligned}
$$

where $0^{\circ}$ is red-purple, $90^{\circ}$ is yellow, $180^{\circ}$ is bluish-green, and $270^{\circ}$ is blue. The colourimetric maturity index (MIc) was calculated by the equation:

$$
\text { MIc }=L^{*} \cdot a^{*} \cdot b^{*-1}
$$

as indicated by Manera et al. (5). MIc indicates four phases, namely: phase 1 with a MIc $<-20$, corresponding to immature fruits with green colour; phase 2 with 


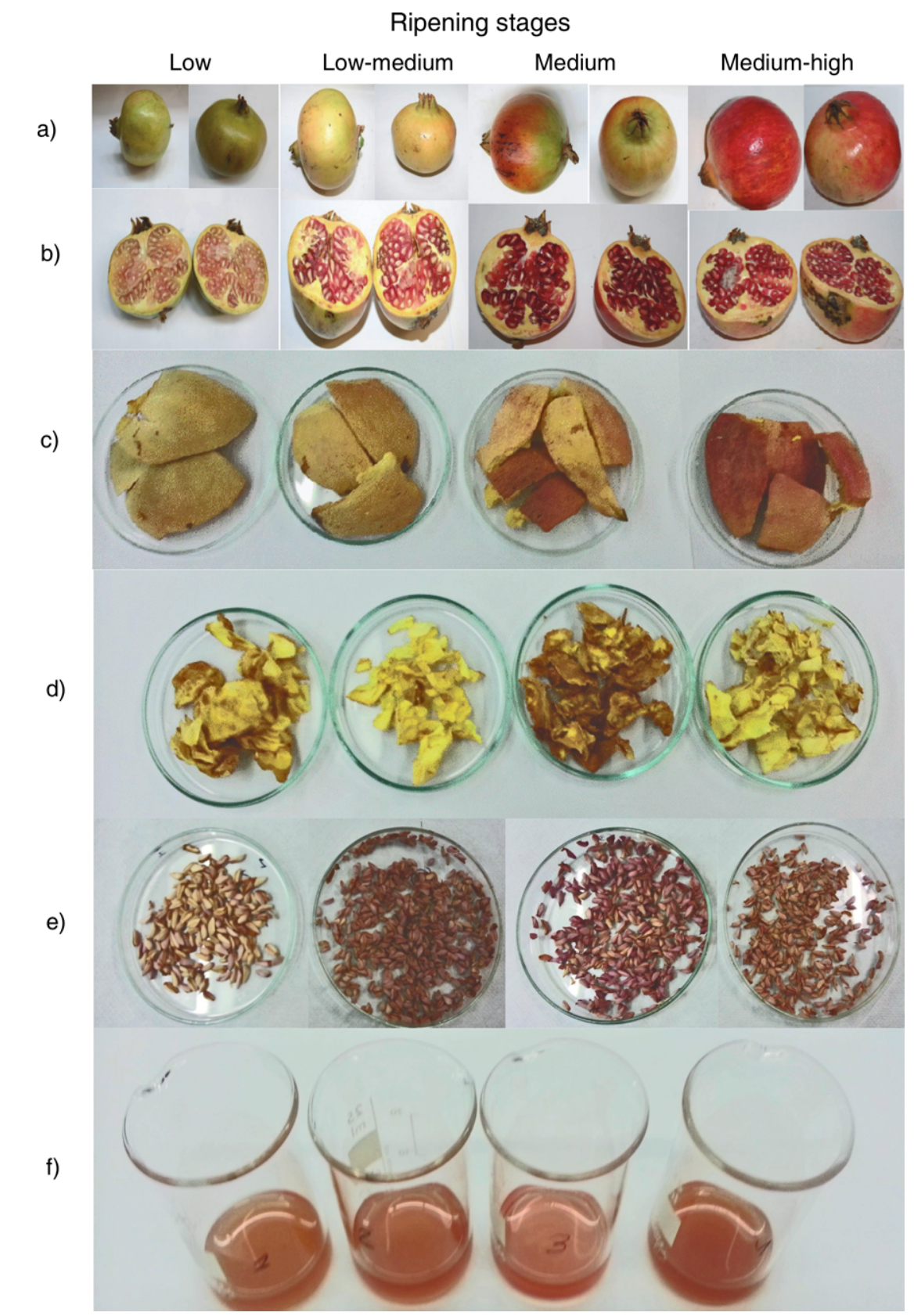

Fig. 1. Pomegranate constituents studied in the present work: a) whole fruit, b) fruit interior, c) skin, d) pellicle, e) seeds and f) juice

$-20 \leq \mathrm{MIc}<0$, indicative of immature fruits, with green colour beginning to change to yellow; phase 3 with $0 \leq \mathrm{MIc}<25$, corresponding to immature fruit with green-yellow colour beginning to turn red; and phase 4 $(\mathrm{MIc} \geq 25)$, indicative of mature fruit with yellowish red or red colour. The diameter and length of seeds were measured with a digital caliper (Powerfix, Berlin, Germany). The moisture content was determined by mass loss at 105 ${ }^{\circ} \mathrm{C}$ until constant mass was reached, according to AOAC method $940.26(21)$.

\section{Total soluble solids, $p H$ and total monomeric anthocyanin content in pomegranate juices}

The content of total soluble solids in and the $\mathrm{pH}$ of the pomegranate juices were measured with an Abbe refrac- tometer (Optic Ivymen System, Madrid, Spain) and potentiometer (370 pH meter; Jenway, Essex, UK), respectively.

The total monomeric anthocyanin content in the pomegranate juices during the four ripening stages was estimated by the $\mathrm{pH}$ differential method, adapted from the methods used by Rajasekar et al. (22) and Bchir et al. (23). This method consists in using two buffer systems: potassium chloride buffer, $\mathrm{pH}=1.0(0.025 \mathrm{M})$, and sodium acetate, $\mathrm{pH}=4.5(0.4 \mathrm{M})$. A volume of $250 \mu \mathrm{L}$ of juice was diluted with buffers at $\mathrm{pH}=1.0$ and 4.5 in 25 -mL flasks and allowed to stand for $30 \mathrm{~min}$ at room temperature. Subsequently, the absorbance was read on a UV-Vis spectrophotometer (Genesys 10UV; Thermo Scientific, Madrid, Spain) at the wavelengths of 510 and $700 \mathrm{~nm}$, and determined by the equation: 


$$
A=\left(A_{510 \mathrm{~nm}}-A_{700 \mathrm{~nm}}\right)_{\mathrm{pH}=1.0}-\left(A_{510 \mathrm{~nm}}-A_{700 \mathrm{~nm}}\right)_{\mathrm{pH}=4.5}
$$

The monomeric anthocyanin pigment concentration was expressed in $\mathrm{mg}$ of cyanidin-3-glucoside (Cy-3-G) per $L$ of juice and determined by the equation:

$\gamma($ monomeric anthocyanins $)=A \cdot M_{\mathrm{r}} \cdot \mathrm{DF} \cdot 1000 /(\varepsilon \cdot 1) \quad / 5 /$ where $A$ is absorbance, $M_{\mathrm{r}}$ is molecular mass (449.2), DF is dilution factor, and $\varepsilon$ is molar absorption coefficient (26900). All measurements were performed in duplicate.

\section{Preparation of pomegranate skin, pellicle, juice and seed extracts}

The extraction of flavonoids, hydrolysable tannins and compounds with antioxidant activity present in the skin, pellicle and seeds of pomegranates was based on the method described by Bchir et al. (23) and Tehranifar et al. (10). Approximately $1 \mathrm{~g}$ of skin, pellicle and seeds was crushed and mixed with $20 \mathrm{~mL}$ of methanol/water solution (4:1, by volume) at room temperature for $5 \mathrm{~h}$ under agitation (RCT Model B; IKA, Staufen, Germany) with a frequency of $50 \times g$. Then, the extracts were filtered, frozen and placed in the lyophiliser (Scanvac, Coolsafe) for 2 days. The extract obtained was redissolved with metha$\mathrm{nol} /$ water to a concentration of $50 \mathrm{mg} / \mathrm{mL}$ and covered with aluminium foil under freezing until further analysis.

The pomegranate juice was only filtered and diluted with methanol/water solution. The extractions were made in duplicate.

\section{Flavonoids}

The total flavonoid content was determined by the method described by Viuda-Martos et al. (24), with slight modifications. A volume of $0.3 \mathrm{~mL}$ of $\mathrm{NaNO}_{2}(5 \%$, by mass per volume) was added to different concentrations of skin, pellicle and seed extracts and juice $(1 \mathrm{~mL})$ and after $5 \mathrm{~min} 0.3 \mathrm{~mL}$ of $\mathrm{AlCl}_{3}(10 \%$, by mass per volume) were added and mixed. After $6 \mathrm{~min}, 2 \mathrm{~mL}$ of $\mathrm{NaOH}(1 \mathrm{M})$ were added. The absorbance was read at $510 \mathrm{~nm}$ and flavonoids were quantified using a standard curve of quercetin $(10-160 \mu \mathrm{g} / \mathrm{mL})$. Flavonoid content in skin, pellicle and seeds was expressed in $\mathrm{mg}$ of quercetin equivalent (QE) per $g$ of extract and in the juice in $\mathrm{mg}$ of QE per 100 $\mathrm{mL}$ of juice. The total flavonoid content was assessed in duplicate.

\section{Hydrolysable tannins}

The content of hydrolysable tannins was determined by the method described by Elfalleh et al. (16). To different concentrations of skin, pellicle and seed extracts and juice $(1 \mathrm{~mL}), 5 \mathrm{~mL}$ of $2.5 \% \mathrm{KIO}_{3}$ were added and stirred for $10 \mathrm{~s}$. The absorbance was measured at $550 \mathrm{~nm}$. The blank corresponded to methanol/water (4:1, by volume). Different concentrations of tannic acid solutions ( 0.025 to $1.6 \mathrm{~g} / \mathrm{L}$ ) were used for calibration. Results were expressed in $\mathrm{mg}$ of tannic acid equivalent (TAE) per $\mathrm{g}$ of skin, pellicle or seed extract or $\mathrm{mg}$ of TAE per $100 \mathrm{~mL}$ of juice. The measurements were done in duplicate.

\section{Determination of total phenolic content}

The total phenolic content of each sample was determined by Folin-Ciocalteu method, described by Singleton and Rossi (25). To $8 \mathrm{~mL}$ of different solutions of pomegranate components (skin, pellicle, seeds or juice) $500 \mu \mathrm{L}$ of Folin-Ciocalteu reagent were added. The blank and standards were prepared similarly, replacing the sample by methanol and standard, respectively. After 3 to $8 \mathrm{~min}$, $1.5 \mathrm{~mL}$ of saturated sodium carbonate solution were added. After $2 \mathrm{~h}$ the absorbance values were read at $765 \mathrm{~nm}$. A calibration curve was obtained with gallic acid ( 0.25 to $5 \mathrm{mg} / \mathrm{L}$ ) and the results were expressed in $\mathrm{mg}$ of gallic acid equivalent (GAE) per $\mathrm{g}$ of skin, pellicle or seed extract or $\mathrm{mg}$ of GAE per $100 \mathrm{~mL}$ of juice. The measurements were done in duplicate.

\section{DPPH radical scavenging activity}

DPPH (2,2-diphenyl-1-picrylhydrazyl) radical scavenging activity was determined by the procedure described by Delgado et al. (26) with some modifications. A mass of $0.0024 \mathrm{~g}$ of DPPH was dissolved in $100 \mathrm{~mL}$ of methanol to obtain a solution of $6.09 \cdot 10-5 \mathrm{~mol} / \mathrm{L}$. The skin, pellicle and seed extract solutions were diluted in methanol/water in a ratio of 4:1 (by volume) and $300 \mu \mathrm{L}$ of these solutions were added to $2.7 \mathrm{~mL}$ of DPPH methanolic solution. After $1 \mathrm{~h}$ in the dark at room temperature, the absorbance was read at $517 \mathrm{~nm}$. Antioxidant activity was expressed as the percentage of scavenging activity according to the following equation:

DPPH radical scavenging activity=

$$
=\left(\frac{A_{\mathrm{DPPH}}-A_{\text {sample }}}{A_{\mathrm{DPPH}}}\right) \cdot 100
$$

where $A_{\mathrm{DPPH}}$ is the absorbance of the DPPH solution and $A_{\text {sample }}$ is the absorbance of the sample. The blank was made with methanol/water in a ratio of $4: 1$ (by volume). The extract concentration providing $50 \%$ of DPPH radical scavenging activity $\left(\mathrm{EC}_{50}\right)$ was calculated from the graph of DPPH radical scavenging activity percentage vs. extract concentration. When using juice, the DPPH radical scavenging activity was determined in $300 \mu \mathrm{L}$ of diluted juice solutions. Each solution was analysed in duplicate.

\section{Reducing power}

The reducing power of the extracts was determined using the procedure described by Delgado et al. (26). To $1.0 \mathrm{~mL}$ of the skin, pellicle and seed extract solutions at different concentrations $2.5 \mathrm{~mL}$ of $0.2 \mathrm{M}$ phosphate buffer $(\mathrm{pH}=6.6)$ and $2.5 \mathrm{~mL}$ of $1 \%$ (by mass per volume) $\mathrm{K}_{3}\left[\mathrm{Fe}(\mathrm{CN})_{6}\right]$ were added. After shaking, the mixture was incubated at $50{ }^{\circ} \mathrm{C}$ for $20 \mathrm{~min}$. A volume of $2.5 \mathrm{~mL}$ of $10 \%$ trichloroacetic acid (by mass per volume) was added with further stirring. The same volume of the mixture was transferred to another test tube, to which $2.5 \mathrm{~mL}$ of distilled water and $0.5 \mathrm{~mL}$ of $0.1 \%$ (by mass per volume) $\mathrm{FeCl}_{3}$ were added. The absorbance values were read at $700 \mathrm{~nm}$. The $\mathrm{EC}_{50}$ values were determined from the concentration of sample solutions that gave an absorbance of 0.5. Each solution was analysed in duplicate.

\section{Statistical analysis}

SPSS Statistical software, v. 18.0 (SPSS Inc., Chicago, IL, USA) was used for the statistical treatment of the data. Analysis of variance (ANOVA) or ANOVA Welch were 
carried out to determine if there were significant differences $(p<0.05)$ between samples. Additionally, post hoc analysis was performed: Tukey's honestly significant difference test if variances in the different groups were identical, or Games-Howell test if they were not. The homogeneity of the variance was tested by Levene's test.

In addition, Pearson's test was applied to analyse the existence of significant relationships between the detected compounds and the antioxidant activity.

\section{Results and Discussion}

\section{Physical characteristics of fruits and seeds of pomegranate (cv. Mollar de Elche) during ripening}

Significant differences in the total mass of the fruit and of its components (skin, pellicles and arils) during ripening (at four maturity stages) were found (Table 1). As expected, the total fruit mass increased from 172 to $412 \mathrm{~g}$ during maturation. The skin mass increased from 55 to $175 \mathrm{~g}$, of pellicle from 2 to $4 \mathrm{~g}$, and of arils from 110 to $221 \mathrm{~g}$. Identical trends were reported by Al-Maiman and Ahmad (12); however, the mass reported by these authors was lower than ours because another pomegranate cultivar was analysed.

Among pomegranate components, arils were those that contributed the most to the fruit mass (between 53 and $65 \%$ ), followed by the skin (31-43\%) and pellicle
(1.0-1.4\%). The percentage of arils decreased during ripening, unlike that of the skin, which increased in the last ripening stage (medium-high), indicating a higher contribution of the skin to the fruit mass at that stage.

According to Fawole and Opara $(27,28)$, the colour of pomegranate skin is not a reliable indicator of their degree of ripening, or that pomegranates are ready to consume. However, it is an important factor in fruit marketing because the consumers tend to select fruit based on the colour (5). Thus, colour determination continues to be of particular relevance. Melgarejo et al. (29) reported that throughout the development and ripening of Spanish Mollar de Elche cultivars, the aril colour changed from white to pinkish-red or red, while the skin of the fruit changed from green to yellow-green, and finally to brownish-yellow with reddish patches, a pattern also observed in the present work (Figs. 1a and b). The skin colour of Mollar de Elche cultivar during the four stages of ripening is described in Table 1. In general, high standard deviations were obtained due to the high variability found in the skin colour of each fruit and among them. The lowest values of $L^{*}$ (lightness) were observed at the beginning (64) and at the end of ripening (63), when the skin became darker. In contrast, higher values of $L^{*}$ (lighter skin) were obtained at the low-medium (70) and medium (68) ripening stages. Our results were different from those reported by Fawole and Opara (28) for the Ruby cultivar where a decrease in $L^{*}$ values during ripening was observed, namely from 48.03 at 54 days after full

Table 1. Physicochemical composition of pomegranate (cv. Mollar de Elche) at four ripening stages

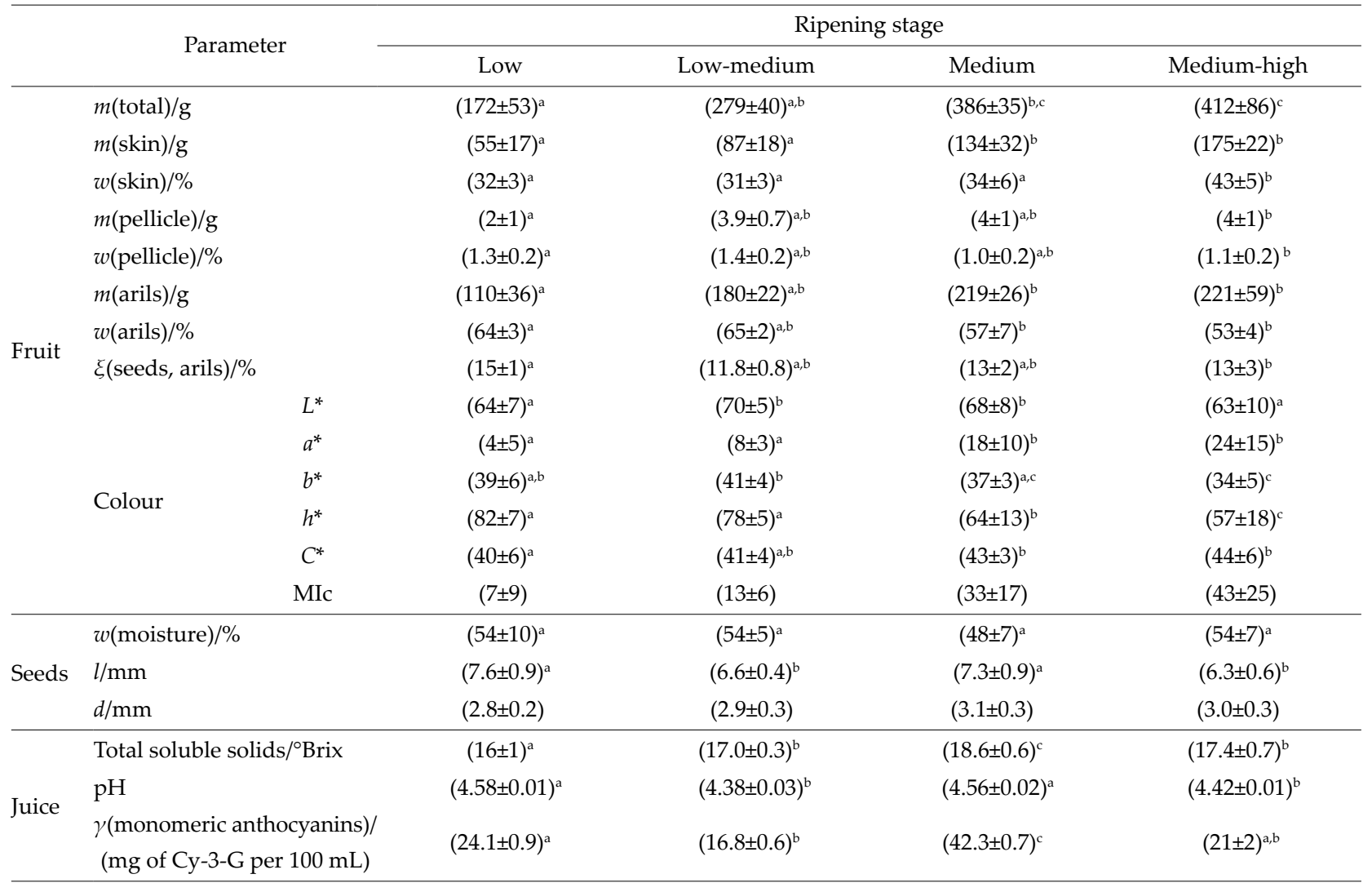

Values are expressed as mean \pm standard deviation $(N=6$, except for colour determination where $N=15)$. Values with the same letter in the same row are not statistically different $(\mathrm{p}>0.05)$. MIc=colourimetric maturity index, $C y-3-G=c y a n i d i n-3$-glucoside 
bloom to 44.15 at 139 days after full bloom. In our work this decrease was not observed because the $L^{*}$ values at low and medium-high ripening stages were not significantly different. Regarding the $a^{*}$ parameter (green-red), significant differences among ripening stages were observed, values ranging from 4 (low) to 24 (medium-high). These results indicated that the skin became more reddish than greenish during ripening. This trend was similar to that described by Fawole and Opara (28), who also observed an increase in $a^{*}$ values from 5.72 to 43.13. A slight variation of the $b^{*}$ values (blue-yellow) was observed, varying between 34 (medium-high) and 41 (lowmedium). The $C^{*}$ value, indicator of the purity or intensity of colour, ranged between 40 and 44, suggesting that the skin at low maturity stage had lower colour intensity than at medium-high ripeness. In the case of hue angle $\left(h^{*}\right)$, the opposite was observed. At low ripeness the highest value (82) was obtained, indicative of yellow colour. On the other hand, at medium-high ripeness the lowest value (57) was determined, indicating a reddish colour. Similar results were reported by Fawole and Opara (28), with $C^{*}$ values between 28.87 and 48.35 , and $h^{*}$ from 76.65 to 30.61 on days 54 and 139 after full bloom, respectively.

According to the colourimetric maturity index (MIc) scale suggested by Manera et al. (5), our pomegranates were in phases 3 and 4 . More specifically, at low and low-medium ripening stages MIcs were equal to 7 and 13, respectively, indicating that pomegranates were in phase 3 $(\mathrm{MIC}=0-25)$. At medium and medium-high ripening stages the MIc values varied between 33 and 43, respectively, corresponding to phase 4 , which must have a MIc higher than 25 . These results indicated that at low and low-medium ripening stages, the fruits were still immature with yellowish-green colour, as observed in Fig. 1a. On the contrary, at medium and medium-high ripening stages, the fruits were ripe with yellow-reddish or red colour (Fig. 1a).

Concerning pomegranate seeds, no significant differences were found in moisture content among the four stages of ripening, varying between 48 (medium) and 54 $\%$ (at all other stages). The length of the seeds ranged between 6.3 and $7.6 \mathrm{~mm}$ (medium-high and low ripening stages, respectively) and the diameter between 2.8 and 3.1 $\mathrm{mm}$ (low and medium ripening stages, respectively). When comparing these results with those of Martínez et al. (30) for the same cultivar, similar results were obtained with lengths between 6.21 and $6.45 \mathrm{~mm}$ and diameters between 1.74 and $2.01 \mathrm{~mm}$.

\section{Chemical characteristics of pomegranate juice during ripening}

The total soluble solid (TSS) content in the juice showed significant differences among the four ripening stages (Table 1). The lowest value was found at the low ripening stage $\left(16^{\circ} \mathrm{Brix}\right)$, as expected. The highest values were obtained at medium (18.6 ${ }^{\circ}$ Brix $)$ and medium-high $\left(17.4{ }^{\circ}\right.$ Brix) ripening stages, indicating juices with higher TSS contents. When comparing our results with those of Al-Maiman and Ahmad (12), who evaluated TSS in pomegranate juice at three ripening stages (unripe, half-ripe and fully ripe), our values were higher than those (16.3 and $\left.16.6^{\circ} \mathrm{Brix}\right)$, with the exception of the low ripening stage. Kulkarni and Aradhya (8) also detected lower TSS values of Ganesh cultivar of 13 and $15.3{ }^{\circ}$ Brix of 40 - and 140-day-old fruits, corresponding to initial and late developmental stages, respectively. Fawole and Opara (27) also detected lower levels of TSS, namely, 10.33 (immature stage) and $15.56^{\circ} \mathrm{Brix}$ (mature stage/fully ripened/harvest 2) in Bhagwa cultivar, and 11.00 (immature stage) and $15.06^{\circ}$ Brix (mature stage/fully ripened/harvest 2) in Ruby cultivar. Fawole and Opara (31) also determined lower TSS values than ours, 10.33 (54 days after full bloom) and $16.18^{\circ}$ Brix (165 days after full bloom) in Bhagwa cultivar. On the contrary, similar values of TSS to ours were obtained by Gil et al. (11) of 16.90 to $17.15^{\circ}$ Brix after 26 to 32 weeks of ripening in the sweet Mollar cultivar. Zarei et al. (13) detected higher TSS values (19.56 ${ }^{\circ}$ Brix) 140 days after fruit set of Rabbab-e-Fars cultivar. In our work the last ripening stage was not the one that had the highest soluble solid content, as reported by Zarei et al. (13). Legua et al. (32) found that the TSS remained constant throughout the ripening of two clones of the Spanish Mollar de Elche cultivar (ME5 and ME17). Overall, these results show that there is a great variability in TSS values among pomegranate cultivars, and the lowest values are always reported at earlier ripening stages.

Regarding $\mathrm{pH}$, it varied slightly during ripening (4.38 at low-medium and 4.56 at medium ripening stages). However, when comparing our results with those of Martínez et al. (30), who evaluated the $\mathrm{pH}$ value of juices from ME15 and ME14 Mollar de Elche cultivars, lower values (4.30) were determined by these authors in relation to any ripening stage assessed in our work. Also Melgarejo et al. (33) obtained lower $\mathrm{pH}$ values (4.06 to 4.11 ) than ours, as well as Gil et al. (11), who determined a $\mathrm{pH}$ value of 4.04 in the 26th and 32nd week, both in the Mollar de Elche cultivar. Al-Maiman and Ahmad (12), while analysing the Taifi cultivar, found lower $\mathrm{pH}$ values of the juice (3.39 to 3.57) than ours, which increased during ripening. Similar situation was also found by Fawole and Opara $(27,31)$ who observed a $\mathrm{pH}$ increase from 3.18 to $3.54-3.57$ in Bhagwa cultivar, and from 3.30 to 3.62 in Ruby cultivar. Zarei et al. (13) also detected a pH increase from 2.65 (20 days after the fruit set) to 3.23 (140 days after the fruit set). Nevertheless, the high $\mathrm{pH}$ values obtained in our study may be due to the similar maturity indices of the pomegranates in this work (phases 3 and 4), with not much different $\mathrm{pH}$ values.

\section{Total monomeric anthocyanin content of juice}

Pomegranate juice is considered a good source of anthocyanins (glucosides and diglucosides of cyanidin, delphinidin and pelargonidin), responsible for the red colour of pomegranate arils (34). The monomeric anthocyanin content in pomegranate juices varied during the ripening stages (Table 1). The monomeric anthocyanin content ranged between 16.8 and $42.3 \mathrm{mg}$ of Cy-3-G per $100 \mathrm{~mL}$ of juice in low-medium and medium ripening stages, respectively, although the highest content of anthocyanins was expected to be found at the medium-high ripening stage (21 mg per $100 \mathrm{~mL}$ of juice), once the juice continued to have a reddish colour (Fig. 1f). Nevertheless, this situation was similar to Kulkarni and Aradhya (8), who observed a rapid increase in anthocyanin content between days 20 and 80, the maximum reached in 100 days (138 
mg per $100 \mathrm{~g}$ of arils), followed by a slight decrease. Our findings are different from those described by Fawole and Opara (27) of Bhagwa cultivar where high levels of anthocyanins in $100 \mathrm{~mL}$ of juice (from 0.01 to $48.61 \mathrm{mg}$ of $\mathrm{Cy}-$ -3-G in 2011 and 0.89 to $45.74 \mathrm{mg}$ of Cy-3-G in 2012) were found. On the contrary, our results at the medium-high ripening stage were similar to Fawole and Opara's (27) of Ruby cultivar, with anthocyanin concentrations in $100 \mathrm{~mL}$ of juice of 0.20 to $24.23 \mathrm{mg}$ of Cy-3-G in 2011 and 0.81 to $27.50 \mathrm{mg}$ of Cy-3-G in 2012 during ripening. Such gradual increase was also described by Gil et al. (11) in the sweet Mollar cultivar, Fawole and Opara (31) in Bhagwa cultivar with an increase in the anthocyanin content between days 54 and 165 after full flowering to a value close to 50 $\mathrm{mg}$ of Cy-3-G per $100 \mathrm{~mL}$ of juice, as well as Zarei et al. (13) from 3.68 to $24.42 \mathrm{mg}$ of Cy-3-G per $100 \mathrm{~g}$ of juice (20 and 140 days after fruit set) in Rabbab-e-Fars cultivar. The small variation in anthocyanin values found in the present work may be due to the fact that pomegranates had only been collected on the basis of the skin colour, a parameter that may not be sufficient to detect differences in chemical properties of the juice.

\section{Flavonoid and hydrolysable tannin contents in}

the skin, pellicle, seeds and juice of pomegranate

(cv. Mollar de Elche) during ripening

When comparing the levels of flavonoids and hydrolysable tannins in different pomegranate components (Table 2), differences between them were detected. The skin was the one with the highest values of flavonoids and hydrolysable tannins in most situations, followed by the pellicle. In the juice, hydrolysable tannins were not detected. These findings are different from those by Gil et al. (35), who detected these compounds $(417.3 \mathrm{mg} / \mathrm{L})$ in juices from Wonderful cultivar. By comparing the contents of hydrolysable tannins of each pomegranate component during maturation, their decrease was observed in skin and pellicle but not in seeds.

Regarding flavonoids, a decrease in their contents in pellicle and skin was found almost in all ripening stages. In the pellicle the flavonoid content decreased about three times between low (667 mg of QE per $\mathrm{g}$ of extract) and medium-high (162 $\mathrm{mg}$ of QE per $\mathrm{g}$ of extract) ripening stages. In skin, a decrease of approx. 2 times was observed between low (821 mg of QE per g of extract) and medium-high (492 mg of QE per $\mathrm{g}$ of extract) ripening stages. By contrast, an increase in the concentration of these compounds was observed in seed and juice when comparing the low with medium-high ripening stages. In seeds, the highest values of flavonoids were obtained in the medium and medium-high ripening stages, 2.9 and $2.7 \mathrm{mg}$ of QE per g of extract, respectively. The juice extracted from the fruit at medium-high ripening stage had the highest content of flavonoids (165 mg of QE per $100 \mathrm{~mL}$ ). These results are different from those described by Fawole and Opara $(27,31)$, who observed a decrease in flavonoids in juice during fruit ripening. More specifically, in the former study the flavonoid values in $100 \mathrm{~mL}$ of juice de-

Table 2. Contents of flavonoids, hydrolysable tannins and total phenolic content, $\mathrm{EC}_{50}$ values in DPPH and reducing power assays of juice, pellicle, seeds and skin of Mollar de Elche pomegranate cultivar at four ripening stages

\begin{tabular}{|c|c|c|c|c|c|c|}
\hline \multirow[b]{2}{*}{ Sample } & \multirow{2}{*}{$\begin{array}{l}\text { Ripening } \\
\text { stage }\end{array}$} & \multicolumn{3}{|c|}{$\gamma /(\mathrm{mg}$ per $100 \mathrm{~mL})$} & \multicolumn{2}{|c|}{$\mathrm{EC}_{50} /(\mathrm{mg}$ of extract per $\mathrm{mL})$} \\
\hline & & Flavonoids & $\begin{array}{l}\text { Hydrolysable } \\
\text { tannins }\end{array}$ & Total phenols & $\mathrm{DPPH}$ & Reducing power \\
\hline \multirow{4}{*}{ Juice } & Low & $(67 \pm 2)^{a}$ & n.d & $(811 \pm 34)^{a}$ & N.D. & N.D. \\
\hline & Low-medium & $(102 \pm 2)^{b}$ & n.d & $(1366 \pm 39)^{b}$ & N.D. & N.D. \\
\hline & Medium & $(89 \pm 10)^{b}$ & n.d & $(1465 \pm 43)^{b}$ & N.D. & N.D. \\
\hline & Medium-high & $(165 \pm 6)^{c}$ & n.d & $(1695 \pm 35)^{c}$ & N.D. & N.D. \\
\hline \multicolumn{5}{|c|}{$w /(\mathrm{mg} / \mathrm{g})$} & & \\
\hline \multirow{4}{*}{ Pellicle } & Low & $(667 \pm 35)^{a}$ & $(1440 \pm 70)^{\mathrm{a}}$ & $(2149 \pm 61)^{\mathrm{a}}$ & $(0.0070 \pm 0.0002)^{\mathrm{a}}$ & $(0.028 \pm 0.001)^{\mathrm{a}}$ \\
\hline & Low-medium & $(706 \pm 14)^{a}$ & $(1273 \pm 212)^{a}$ & $(1954 \pm 33)^{a}$ & $(0.0122 \pm 0.0004)^{\mathrm{a}}$ & $(0.045 \pm 0.001)^{\mathrm{a}}$ \\
\hline & Medium & $(617 \pm 28)^{a}$ & $(1288 \pm 70)^{\mathrm{a}}$ & $(1676 \pm 29)^{a}$ & $(0.0072 \pm 0.0002)^{\mathrm{a}}$ & $(0.036 \pm 0.001)^{\mathrm{a}}$ \\
\hline & Medium-high & $(162 \pm 1)^{\mathrm{b}}$ & $(436 \pm 69)^{\mathrm{b}}$ & $(248 \pm 48)^{\mathrm{b}}$ & $(0.0332 \pm 0.0001)^{\mathrm{b}}$ & $(0.326 \pm 0.006)^{\mathrm{b}}$ \\
\hline \multirow{4}{*}{ Seeds } & Low & $(1.9 \pm 0.1)^{\mathrm{a}}$ & $(2.6 \pm 0.2)^{\mathrm{a}}$ & $(8.12 \pm 0.12)^{\mathrm{a}}$ & $(1.1 \pm 0.1)^{\mathrm{a}}$ & $(9.49 \pm 0.06)^{\mathrm{a}}$ \\
\hline & Low-medium & $(1.5 \pm 0.1)^{\mathrm{b}}$ & $(2.4 \pm 0.4)^{\mathrm{a}}$ & $(7.36 \pm 0.11)^{\mathrm{b}}$ & $(1.54 \pm 0.06)^{\mathrm{b}}$ & $(8.73 \pm 0.03)^{\mathrm{b}}$ \\
\hline & Medium & $(2.9 \pm 0.1)^{c}$ & $(12 \pm 1)^{b}$ & $(8.64 \pm 0.01)^{c}$ & $(1.77 \pm 0.04)^{c}$ & $(4.76 \pm 0.09)^{c}$ \\
\hline & Medium-high & $(2.7 \pm 0.1)^{c}$ & $(6.4 \pm 0.6)^{c}$ & $(8.43 \pm 0.04)^{c}$ & $(1.37 \pm 0.06)^{\mathrm{b}}$ & $(5.73 \pm 0.06)^{\mathrm{d}}$ \\
\hline \multirow{4}{*}{ Skin } & Low & $(821 \pm 33)^{a}$ & $(1483 \pm 150)^{\mathrm{a}}$ & $(2997 \pm 65)^{\mathrm{a}}$ & $(0.0235 \pm 0.0008)^{\mathrm{a}}$ & $(0.038 \pm 0.001)^{\mathrm{a}}$ \\
\hline & Low-medium & $(784 \pm 17)^{\mathrm{a}, \mathrm{b}}$ & $(1304 \pm 53)^{a, b}$ & $(3387 \pm 64)^{b}$ & $(0.0180 \pm 0.0006)^{\mathrm{b}}$ & $(0.043 \pm 0.001)^{\mathrm{a}}$ \\
\hline & Medium & $(721 \pm 17)^{\mathrm{b}}$ & $(1073 \pm 107)^{\mathrm{b}, \mathrm{c}}$ & $(2997 \pm 62)^{a}$ & $(0.0160 \pm 0.0005)^{c}$ & $(0.057 \pm 0.001)^{\mathrm{b}}$ \\
\hline & Medium-high & $(492 \pm 36)^{c}$ & $(774 \pm 167)^{c}$ & $(2039 \pm 40)^{c}$ & $(0.0163 \pm 0.0003)^{c}$ & $(0.057 \pm 0.001)^{c}$ \\
\hline
\end{tabular}

Values are expressed as mean \pm standard deviation $(N=6)$. Values with the same letter in the same column are not statistically different ( $\mathrm{p}>0.05)$. Flavonoid content is expressed in $\mathrm{mg}$ of quercetin equivalent per $\mathrm{g}$ of extract or $100 \mathrm{~mL}$ of juice, hydrolysable tannins are expressed in $\mathrm{mg}$ of tannic acid equivalent per $\mathrm{g}$ of extract or $100 \mathrm{~mL}$ of juice and total phenols are expressed in mg of gallic acid equivalent per $\mathrm{g}$ of extract or $100 \mathrm{~mL}$ of juice. $\mathrm{n} . \mathrm{d}=$ not detected, N.D.=not determined 
creased during ripening of Bhagwa cultivar from 1459.94 to $201.57 \mathrm{mg}$ of catechin equivalent (CAE) in 2011 and from 1045.62 to $150.99 \mathrm{mg}$ of CAE in 2012 (27). In Ruby cultivar the flavonoid levels in $100 \mathrm{~mL}$ of juice decreased from 752.18 to $397.27 \mathrm{mg}$ of CAE in 2011 and from 529.19 to $309.93 \mathrm{mg}$ of CAE in 2012. In the latter study, the flavonoid content in $100 \mathrm{~mL}$ of juice was approx. $1500 \mathrm{mg}$ of CAE after 54 days, decreasing to a value below $500 \mathrm{mg}$ of CAE in 165 days (31). However, the difference observed between our work and these studies may be in the fact that MIc values of pomegranates used in this work corresponded to phases 3 and 4, which indicated that the analysed fruits were already in a more advanced ripening stage than those studied by Fawole and Opara $(27,31)$, which had lower flavonoid contents. Again, our study shows that only observing the changes in the skin colour may not be sufficient to detect significant differences in the chemical properties of juice.

\section{Total phenolic content and antioxidant activity of the skin, pellicle, seeds and juice of pomegranate (cv. Mollar de Elche) during ripening}

The highest values of total phenolic content were obtained in the extracts of skin and pellicle (Table 2). Li et al. (36) had already reported that the pomegranate skin showed a higher antioxidant activity than pulp and seeds. According to Pande and Akoh (37), this can be attributed to its high content of tannins, especially punicalagin isomers. Phenolic compounds, including flavonoids, anthocyanins and tannins, are referred to as the main group of antioxidant phytochemicals with interesting properties due to their biological activities and free radical scavenging capacity (16).

When comparing the medium-high with the other ripening stages, it was found that the content of total phenols in the extracts of the skin and pellicle markedly decreased. By contrast, in seed extracts the last two ripening stages were those with the highest values of total phenols. In the juice, total phenols also increased from 811 (low ripening stage) to 1695 (medium-high ripening stage) $\mathrm{mg}$ of GAE per $100 \mathrm{~mL}$, possibly as the result of an increase in the content of flavonoids.

Regarding DPPH free radical scavenging activity and reducing power, it was found that the antioxidant activity

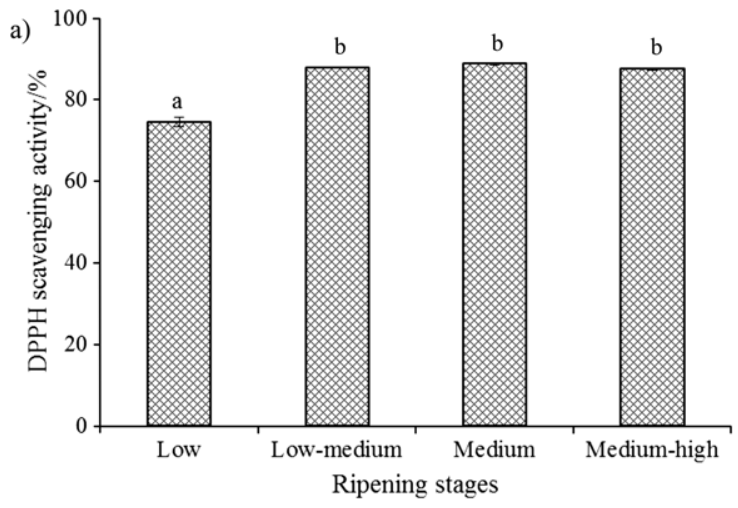

of the skin, pellicle and seed extracts increased with the increase of extract concentration (data not shown). Observing the $\mathrm{EC}_{50}$ values obtained for the DPPH free radical scavenging activity and reducing power (Table 2), it was found that the seed extracts had the lowest antioxidant potential, since they showed the highest $\mathrm{EC}_{50}$ values, which are inversely proportional to the antioxidant activity. The highest DPPH free radical scavenging capacity of the seeds $\left(E_{50}=1.1 \mathrm{mg}\right.$ of seed extract per $\mathrm{mL}$ ) was obtained in pomegranates at low ripening stage. Similar results were observed for the pellicle $\left(\mathrm{EC}_{50}=0.0070 \mathrm{mg}\right.$ of pellicle extract per $\mathrm{mL}$ ). The skin had the highest antioxidant activity in the two most advanced ripening stages. Similar behaviour was observed in the juice (Fig. 2a). An increase of $17.4 \%$ in the antioxidant activity of the juice was observed from the low to medium-high ripening stages. Our results are similar to those reported by Kulkarni and Aradhya (8) for the antioxidant activity measured by DPPH free radical scavenging capacity in pomegranate juice of Ganesh cultivar during ripening, where an increase of $10.6 \%$ was observed between the days 60 and 80 of fruit development, remaining almost constant thereafter.

Regarding reducing power (Table 2, Fig. 2b), the lowest antioxidant activity was obtained at the medium-high ripening stage of pellicle $(0.326 \mathrm{mg}$ of pellicle extract per $\mathrm{mL})$ and skin $(0.057 \mathrm{mg}$ of skin extract per $\mathrm{mL})$, whereas in the seeds and juice the highest reducing power was observed at the medium and medium-high ripening stages.

\section{Correlation among flavonoid, hydrolysable tannin and total phenolic contents, DPPH radical scavenging activity and reducing power}

Table 3 shows the correlation among flavonoid, hydrolysable tannin and total phenolic contents, DPPH radical scavenging activity and reducing power of the skin, pellicle and seeds, as well as juice. It was found that the contents of flavonoids and hydrolysable tannins showed significantly positive correlations with total phenolic content, namely 0.992 and 0.962 , respectively. Negative correlations of the $\mathrm{EC}_{50}$ values in $\mathrm{DPPH}$ and reducing power assays with flavonoids and hydrolysable tannins were obtained, with slightly higher correlation values for the hydrolysable tannins. All of these results show the impor-

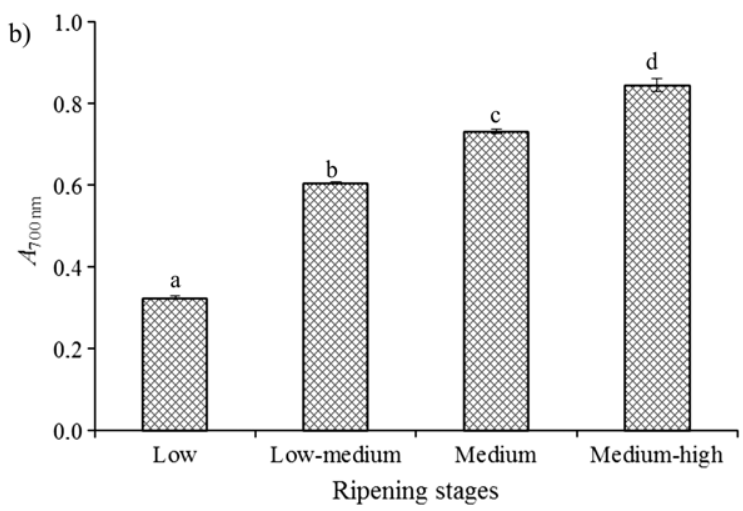

Fig. 2. Antioxidant activity of juice at four ripening stages of the pomegranate Mollar de Elche cultivar: a) DPPH radical scavenging activity, and $\mathrm{b}$ ) reducing power $\left(A_{700 \mathrm{~nm}}\right)$ 
Table 3. Pearson's correlation values for flavonoid, hydrolysable tannin and total phenolic content, $\mathrm{EC}_{50}$ values in DPPH and reducing power assays of pellicle, seeds, skin and juice of Mollar de Elche pomegranate cultivar

\begin{tabular}{|c|c|c|c|c|}
\hline \multirow{2}{*}{ Pellicle, seeds and skin } & \multirow{2}{*}{ Hydrolysable tannins } & \multirow{2}{*}{ Total phenols } & \multicolumn{2}{|c|}{$\mathrm{EC}_{50}$} \\
\hline & & & DPPH & Reducing power \\
\hline Flavonoids & $0.972^{* *}$ & $0.992^{* *}$ & $-0.857^{* *}$ & $-0.837^{* *}$ \\
\hline Hydrolysable tannins & - & $0.962^{* *}$ & $-0.863^{* *}$ & $-0.845^{* *}$ \\
\hline Total reducing power & - & - & $-0.855^{* *}$ & $-0.831^{* *}$ \\
\hline $\mathrm{DPPH}\left(\mathrm{EC}_{50}\right)$ & - & - & - & $-0.881^{* *}$ \\
\hline \multicolumn{5}{|l|}{ Juice } \\
\hline Flavonoids & & $0.825^{* *}$ & $-0.586^{* *}$ & $-0.676^{* *}$ \\
\hline Total reducing power & & - & $-0.907^{* *}$ & $-0.964^{* *}$ \\
\hline $\mathrm{DPPH}\left(\mathrm{EC}_{50}\right)$ & & - & - & $-0.979^{* *}$ \\
\hline Reducing power $\left(\mathrm{EC}_{50}\right)$ & & - & & - \\
\hline
\end{tabular}

Correlation is significant at ${ }^{* *} \mathrm{p}<0.01$

tance of these compounds in antioxidant activity, as suggested by Elfalleh et al. (16). Moreover, negative correlations between total phenolic content and $\mathrm{EC}_{50}$ values in $\mathrm{DPPH}(-0.855)$ and reducing power $(-0.831)$ assays were found, suggesting that the determined phenolic compounds have DPPH free radical scavenging capacity and reducing properties.

Similar results were obtained in the juice (Table 3). A positive correlation between flavonoid and total phenolic content (0.825) and negative correlations between flavonoid and $\mathrm{EC}_{50}$ values in DPPH $(-0.586)$ and reducing power $(-0.676)$ assays were determined, indicating that flavonoids have an important role in the antioxidant properties of pomegranate juice.

\section{Conclusions}

As expected, the fruit mass and skin colour changed during pomegranate ripening. The lowest fruit mass was obtained in low ripening stages; however, the percentage of arils was always higher than $50 \%$. Regarding the skin colour, the greatest variations were observed in $a^{*}$ and $h^{*}$ values during fruit ripening. The $a^{*}$ values increased and $h^{*}$ decreased during ripening, indicating a reddish colour. The content of total soluble solids in the juice changed slightly, increasing from the lowest ripening stage towards the most advanced ripening stages.

The juices obtained from pomegranates at the lowest ripening stage had the lowest flavonoid and total phenolic contents, DPPH free radical scavenging capacity and reducing power, but at higher ripening stages the antioxidant activity increased. In skin and pellicle, differences in flavonoid and hydrolysable tannin contents were observed only at the highest ripening stage. Nevertheless, in general the skin and pellicle extracts of pomegranate had high levels of flavonoids, tannins and antioxidant activity. Therefore, these by-products are still a potential source of antioxidants, as they may be preferred by consumers due to their natural origin. Accordingly, they may be valorised for the production of nutraceuticals or functional food ingredients.

\section{Acknowledgements}

Authors are grateful to POCTEP, Programa de Cooperação Transfronteiriça Espanha-Portugal for financial support through the Project 'RED/AGROTEC - Experimentation network and transfer for development of agricultural and agroindustrial sectors between Spain and Portugal'.

\section{References}

1. A.C. Sánchez, A.A.C. Barrachina, Pomegrante grown in Spain. Punicalagin of pomegranate juice and pomegranate extract in the functional food of the future. Universidad Miguel Hernández, Múrcia, Spain; 2011. Available from: http://www. granatumplus.es (in Spanish).

2. Y. Costa, P. Melgarejo, A study of the production costs of two pomegranate varieties grown in poor quality soils. In: Melgarejo P, Martínez-Nicolás JJ, Martínez-Tomé J, editors. Production, processing and marketing of pomegranate in the Mediterranean region: Advances in research and technology, Zaragoza, Spain: CIHEAM; 2000. pp. 49-53.

3. Stover E, Mercure EW. The pomegranate: A new look at the fruit of paradise. HortSci. 2007;42:1088-92.

4. Glozer K, Ferguson L. In: Bell M, editor. Pomegranate production in Afghanistan. Davis, USA: UC Davis; 2011.

5. Manera FJ, Legua P, Melgarejo P, Brotons JM, Hernández F, Martínez JJ. Determination of a colour index for fruit of pomegranate varietal group 'Mollar de Elche'. Sci Hort. 2013; 150:360-64.

http://dx.doi.org/10.1016/j.scienta.2012.11.036

6. Shwartz E, Glazer I, Bar-Ya'akov I, Matityahu I, Bar-Ilan I, Holland D, et al. Changes in chemical constituents during the maturation and ripening of two commercially important pomegranate accessions. Food Chem. 2009;115:965-73. http://dx.doi.org/10.1016/j.foodchem.2009.01.036

7. Fawole OA, Opara UL. Developmental changes in maturity indices of pomegranate fruit: A descriptive review. Sci Hort. 2013;159:152-61.

http://dx.doi.org/10.1016/j.scienta.2013.05.016

8. Kulkarni AP, Aradhya SM, Chemical changes and antioxidant activity in pomegranate arils during fruit development. Food Chem. 2005;93:319-24.

http://dx.doi.org/10.1016/j.foodchem.2004.09.029 
9. Mirdehghan $\mathrm{SH}$, Rahemi M. Seasonal changes of mineral nutrients and phenolics in pomegranate (Punica granatum L.) fruit. Sci Hort. 2007;111:120-7.

http://dx.doi.org/10.1016/j.scienta.2006.10.001

10. Tehranifar A, Zarei M, Nematia Z, Esfandiyari B, Vazifeshenas MR. Investigation of physico-chemical properties and antioxidant activity of twenty Iranian pomegranate (Punica granatum L.) cultivars. Sci Hort. 2010;126:180-5. http://dx.doi.org/10.1016/j.scienta.2010.07.001

11. Gil MI, Sánchez R, Marín G, Artés F. Quality changes in pomegranates during ripening and cold storage. Z Lebensm Unters Forsch. 1996;202:481-5.

12. Al-Maiman SA, Ahmad D. Changes in physical and chemical properties during pomegranate (Punica granatum L.) fruit maturation. Food Chem. 2002;76:437-41. http://dx.doi.org/10.1016/S0308-8146(01)00301-6

13. Zarei M, Azizi M, Bashir-Sadr Z. Evaluation of physicochemical characteristics of pomegranate (Punica granatum L.) fruit during ripening. Fruits. 2011;66:121-9. http://dx.doi.org/10.1051/fruits/2011021

14. Hernández F, Melgarejo P, Tomás-Barberán FA, Artés F. Evolution of juice anthocyanins during ripening of new selected pomegranate (Punica granatum) clones. Eur Food Res Technol. 1999;210:39-42. http://dx.doi.org/10.1007/s002170050529

15. Eghdami A, Moghaddasi MS, Sadeghi F. Determination of antioxidant activity of juice and peel extract of three variety of pomegranate and clinical study. Adv Environm Biol. 2011; 5:2282-7.

16. Elfalleh W, Hannachi H, Tlili N, Yahia Y, Nasri N, Ferchichi A. Total phenolic contents and antioxidant activities of pomegranate peel, seed, leaf and flower. J Med Plants Res. 2012; 6:4724-30. http://dx.doi.org/10.5897/JMPR11.995

17. Gözlekçi Ş, Saraçoğlu O, Onursal E, Özgen M. Total phenolic distribution of juice, peel, and seed extracts of four pomegranate cultivars. Pharmacogn Mag. 2011;7:161-4. http://dx.doi.org/10.4103/0973-1296.80681

18. Meier U, editor. BBCH Monograph - Growth stages of monoand dicotyledonous plants. Bonn, Germany: Federal Biological Research Centre for Agriculture and Forestry; 2001.

19. Melgarejo P, Salazar D. Treaty of fruit production for arid and semi-arid areas: carob, pomegranate and jujube. Vol II. Madrid, Spain: Mundi-Prensa Libros S.A; 2003 (in Spanish).

20. Zaouay F, Mena P, Garcia-Viguera C, Mars M. Antioxidant activity and physico chemical properties of Tunisian grown pomegranate (Punica granatum L.) cultivars. Ind Crop Prod. 2012;40:81-9.

http://dx.doi.org/10.1016/j.indcrop.2012.02.045

21. AOAC Official Method 940.26. Ash of Fruits and Fruit Products. Gaithersburg, MD, USA: AOAC International; 2000.

22. Rajasekar D, Akoh CC, Martino KG, MacLean DD. Physicochemical characteristics of juice extracted by blender and mechanical press from pomegranate cultivars grown in Georgia. Food Chem. 2012;133:1383-93.

http://dx.doi.org/10.1016/j.foodchem.2012.02.025

23. Bchir B, Besbes S, Karoui R, Attia H, Paquot M, Blecker C. Effect of air-drying conditions on physico-chemical properties of osmotically pre-treated pomegranate seeds. Food Bioprocess Tech. 2012;5:1840-52. http://dx.doi.org/10.1007/s11947-010-0469-3

24. Viuda-Martos M, Ruiz-Navajas Y, Fernández-López J, Sendra E, Sayas-Barberá E, Pérez-Álvarez JA. Antioxidant properties of pomegranate (Punica granatum L.) bagasses ob- tained as co-product in the juice extraction. Food Res Int. 2011;44:1217-23.

http://dx.doi.org/10.1016/j.foodres.2010.10.057

25. Singleton VL, Rossi Jr JA. Colorimetry of total phenolics with phosphomolybdic-phosphotungstic acid reagents. Am J Enol Vitic. 1965;16:144-58.

26. Delgado T, Malheiro R, Pereira JA, Ramalhosa E. Hazelnut (Corylus avellana L.) kernels as a source of antioxidants and their potential in relation to other nuts. Ind Crop Prod. 2010;32:621-6. http://dx.doi.org/10.1016/j.indcrop.2010.07.019

27. Fawole OA, Opara UL. Seasonal variation in chemical composition, aroma volatiles and antioxidant capacity of pomegranate during fruit development. Afr J Biotechnol. 2013;12: 4006-19. http://dx.doi.org/10.5897/AJB2013.12337

28. Fawole OA, Opara UL. Changes in physical properties, chemical and elemental composition and antioxidant capacity of pomegranate (cv. Ruby) fruit at five maturity stages. Sci Hort. 2013;150:37-46. http://dx.doi.org/10.1016/j.scienta.2012.10.026

29. Melgarejo P, Martinez-Valero R, Guillamón JM, Miró M, Amorós A. Phenological stages of the pomegranate tree $(\mathrm{Pu}-$ nica granatum L.). Ann Appl Biol. 1997;130:135-40.

30. Martínez JJ, Melgarejo P, Hernández F, Salazar DM, Martínez R. Seed characterisation of five new pomegranate (Punica granatum L.) varieties. Sci Hort. 2006;110:241-6. http://dx.doi.org/10.1016/j.scienta.2006.07.018

31. Fawole OA, Opara UL. Effects of maturity status on biochemical content, polyphenol composition and antioxidant capacity of pomegranate fruit arils (cv. 'Bhagwa'). S Afr J Bot. 2013;85:23-31. http://dx.doi.org/10.1016/j.sajb.2012.11.010

32. Legua $\mathrm{P}$, Melgarejo $\mathrm{P}$, Martínez M, Hernández F. Evolution of sugars and organic acid content in three pomegranate cultivars (Punica granatum L.). In: Melgarejo P, Martínez-Nicolás JJ, Martínez-Tomé J, editors. Production, processing and marketing of pomegranate in the Mediterranean region: Advances in research and technology, Mediterranean Options: Series A. Mediterranean Seminars, No. 42. Zaragoza, Spain: CIHEAM; 2000. pp. 99-104.

33. Melgarejo P, Calín-Sánchez A, Vázquez-Aráujo L, Hernández F, Martínez JJ, Legua P, Carbonell-Barrachina ÁA. Volatile composition of pomegranates from 9 Spanish cultivars using headspace solid phase microextraction. J Food Sci. 2011;76:114-20.

http://dx.doi.org/10.1111/j.1750-3841.2010.01945.x

34. Ozgen M, Durgaç C, Serçe S, Kaya C. Chemical and antioxidant properties of pomegranate cultivars grown in the Mediterranean region of Turkey. Food Chem. 2008;111:703-6. http://dx.doi.org/10.1016/j.foodchem.2008.04.043

35. Gil MI, Tomás-Barberán FA, Hess-Pierce B, Holcroft DM, Kader AA. Antioxidant activity of pomegranate juice and its relationship with phenolic composition and processing. J Agric Food Chem. 2000;48:4581-9. http://dx.doi.org/10.1021/jf000404a

36. Li Y, Guo C, Yang J, Wei J, Xu J, Cheng S. Evaluation of antioxidant properties of pomegranate peel extract in comparison with pomegranate pulp extract. Food Chem. 2006;96: 254-60. http://dx.doi.org/10.1016/j.foodchem.2005.02.033

37. Pande G, Akoh CC. Antioxidant capacity and lipid characterization of six Georgia-grown pomegranate cultivars. J Agric Food Chem. 2009;57:9427-36. http://dx.doi.org/10.1021/jf901880p 